\title{
Application of Electric Circuit Theory to the Growing Process of Stress Corrosion Cracking in a Chloride Environment*
}

\author{
Yasoji Tsukaue** \\ * Material Research Department, Kure Research Laboratory, Babcock-Hitachi K.K.,
}

\begin{abstract}
A mathematical model to explain quantitatively the existence of the threshold stress intensity factor $\left(K_{\mathrm{Iscc}}\right)$ and the growth rate $(\mathrm{d} a / \mathrm{d} t)$ of stress corrosion cracking (SCC) of 18-8 austenitic stainless steel in a chloride environment at room temperature was investigated using electric circuit theory applied to the closed corrosion path with a metal-electrode (1 anode- 2 cathode)-solution system of SCC crack geometry. Several conceptual assumptions and simplifications of the equations were attempted to derive the circuit current and the concentration of the chemical components of solution in SCC crack. It is predicted from the derived equation that the accumulation of solution in SCC crack may arise in the condition of $f-\mathrm{C}_{\mathrm{c}_{1}}{ }^{-} \times K \times g_{2}>0$

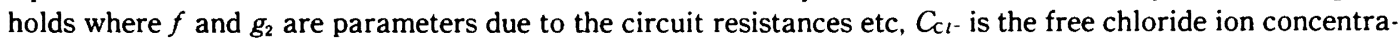
tion inside the crack, and $K$ is the equilibrium constant or stability constant of the crack solution. A relation between $\mathrm{d} a / \mathrm{d} t$ and applied external force was simulated using an anode dissolution parameter relating to stress intensity factor $K_{1}$. The SCC growth rate of about $10^{-8} \mathrm{~m} / \mathrm{s}$ obtained is reasonable compared with the data in the literatures. A parameter $\varepsilon\left(K_{\mathrm{Iscc}}\right)$ corresponding to $K_{\mathrm{Iscc}}$ was derived and it may predict quanitatively the concentration dependence of $K_{\mathrm{Iscc}}$ regarding metallic ions and hydrogen ions.
\end{abstract}

Key words : electric circuit, crack, stress crack corrosion, pit, crevice, threshold stress intensity factor, hydrolysis, chloride, complexes, $\mathrm{pH}$, accumulation, 18.8 stainless steel

\section{Introduction}

The relations between the SCC crack growth rate $(\mathrm{d} a / \mathrm{d} t)$ and the stress intensity factor $\left(K_{1}\right)$ for $18-8$ austenitic stainless steel in chloride environments have been investigated experimentally, and the existence of the threshold stress intensity factor $\left(K_{\mathrm{Iscc}}\right)$, an. important parameter in engineering, was confirmed $^{1 / 25}$. However, quantitative studies on the mechanism of the existence of $K_{\mathrm{Iscc}}$ have been scarce to date.

The SCC of the 18-8 austenitic stainless steel pipes as heat-exchanger by cooling water containing chloride ions takes place often underneath the deposits such as calcium salt or corrosion product ${ }^{6}$. In this case, since it becomes difficult that the chemical components in crack solution move into the bulk solution by the deposits, several components may accumulate in it ${ }^{11,7)}$.

The author ${ }^{8)}$ reported quantitative estimates of the process of growing of localized corrosions using an electrical network simulated corrosion pit in a chloride solution. In this paper, it was attempted to model the electric circuits of the whole SCC corrosion paths with a metal - electrode ( 1 anode - 2 cathode) - solution system of SCC crack geometry and quantitatively to elucidate the conditions for the existence of $K_{\text {Iscc }}$ by

\footnotetext{
- This research was partially presented at JSCE,CORROSION '95 (May 1995, Tokyo)

-. 3-36, Takara-cho, Kure-shi, Hiroshima-ken 737-0029, Japan
}

simplifying the equations and considering the equivalence between the simulated results of the SCC crack growth rate and the experimental data reported in the literature. The electric circuit theory was applied to the closed corrosion path with a metal-electrode ( 1 anode-2 cathode) -solution system of SCC crack geometry, the potential drop equations were constructed, and the circuit resistance was estimated.

\section{Mathematical Model}

\subsection{SCC model conditions}

The electric circuit model and the dimensions of the SCC crack are shown with the flow of charges in Fig. 1. The data in Fig. 1 are used to clarify the existence of $K_{\mathrm{IScc}}$ and estimate quantitatively the SCC crack growth rate for 18-8 austenitic stainless steel in a chloride environment at room temperature. This model is based on the following general assumptions for making the electric circuit via a simplification of the corrosion phenomena.

(1) As shown in Fig. 1, the aspect ratio is so high that the crack walls can be regarded as paralle ${ }^{9,10}$.

(2) It is assumed that a uniform strain is formed on a bare metal of the crack tip by the external force.

(3) The crack walls are covered by an oxidation film under the tensile stress conditions.

(4) Crack growth can be considered to be mainly due to the slip-dissolution model since the crack 


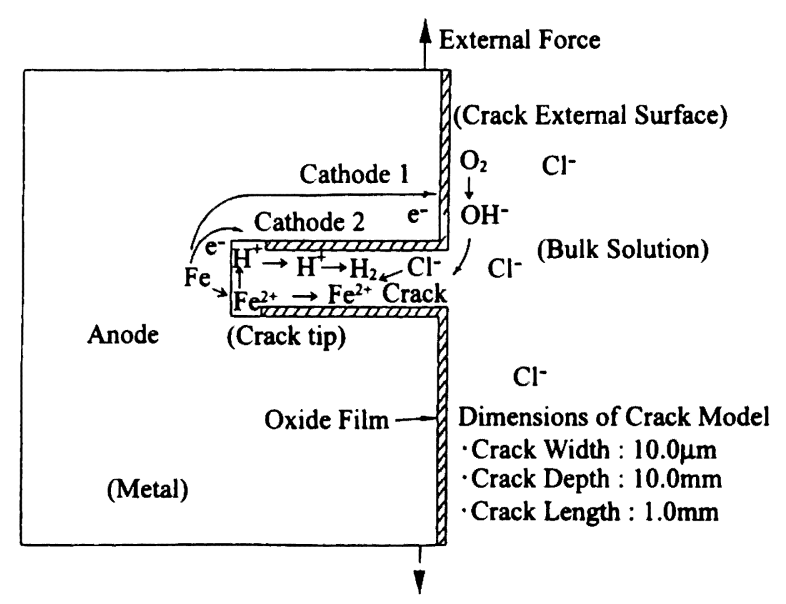

Fig. 1 SCC crack geometry and flows of electrons and various ions in the neighborhood of the crack.

tip may be exposed to the bare metal in the highly concentrated chloride solution ${ }^{11}$.

(5) Metal dissolution (Anode) is caused only at the crack tip.

(6) The reduction of oxygen (Cathode 1) occurs only on the outside surface of the crack.

(7) The reduction of hydrogen (Cathode 2) proceeds only on the side walls.

(8) This mathematical model consists of two closed electric circuits as shown in Fig. 2. One is an anode/solution/cathode $1 /$ metal/anode system. The other is an anode/solution/cathode $2 /$ metal/anode system.

(9) Hydrogen ions produced in the crack flow along the crack wall, and the flowing area is a half of the cross section of the crack. The center of cathode 2 at which the circuit current flows is a half of the crack depth.

(10) Only hydrolysis reaction accompanied with the formation of chloride-complex arises at very high velocity to form the hydrogen ions in the $\mathrm{crack}^{12), 13)}$.

(11) The free chloride ion concentration inside the SCC crack is approximately equal to that in the bulk solution even when chloride complex accu. mulates inside the $\mathrm{crack}^{14), 15)}$.

(12) The volume of accumulated solution inside the crack is assumed as a constant in the SCC crack growth process, and the concentration of the chemical components in it is everywhere uniform and changes with time.

(13) The chemical components in the accumulated solution do not move into the bulk solution in the crack growing process.

\subsection{Chemical reactions}

The following electrochemical reactions in the dissolution of the individual components of $18-8$ stainless

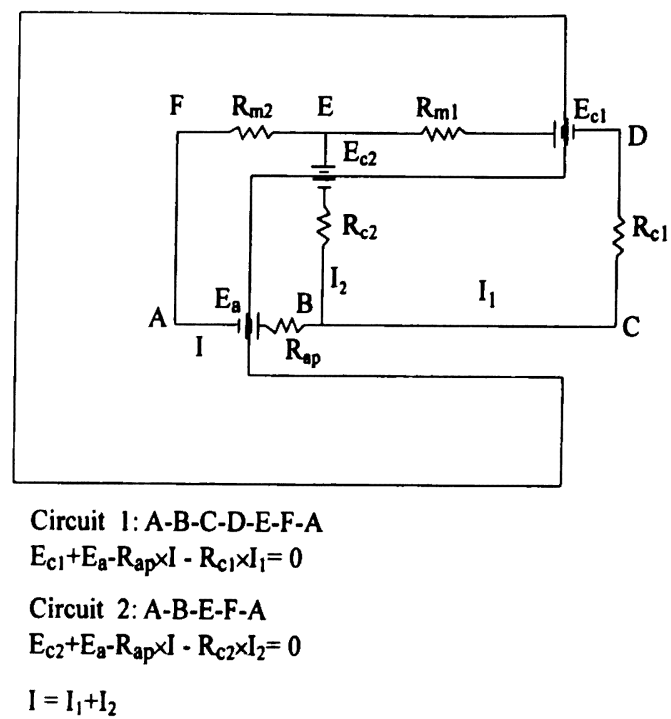

Fig. 2 Electric circuits constituted of circuit 1 and circuit 2 simulated the flow of electron and various ions shown in Fig. 1

steel are assumed on the electrodes and in the crack solution.

- Crack tip (anode)

$\mathrm{M}=\mathrm{M}^{2+}+z \mathrm{e}^{-}$

where $M$ is metal, $z=2$ or 3 .

- External surface of the crack (cathode 1 : reduction of oxygen)

$\mathrm{O}_{2}+2 \mathrm{H}_{2} \mathrm{O}+4 \mathrm{e}^{-}=4 \mathrm{OH}^{-}$

- Crack walls (cathode 2: reduction of hydrogen ions)

$2 \mathrm{H}^{+}+2 \mathrm{e}^{-}=\mathrm{H}_{2}$

- Crack solution

It is assumed that the only major formation reaction of hydroxy-chloro-complexes ${ }^{28)}$ arises as a result of the hydrolysis reaction in the crack solution.

Although various reactions of $\mathrm{M}^{z+}+n \mathrm{Cl}^{-}+m \mathrm{H}_{2} \mathrm{O}$ $\rightarrow \mathrm{M}(\mathrm{OH})_{m} \mathrm{Cl}_{n}{ }^{-(m+n-z)}+\mathrm{H}^{+}$with respect to $z, m$, and $n$ can be considered, Equation (4) corresponding to $m=1$ was used for a quantitative estimation ${ }^{13), 14), 16)}$.

$$
\mathrm{M}^{z+}+\mathrm{H}_{2} \mathrm{O}+n \mathrm{Cl}^{-}=\mathrm{M}(\mathrm{OH}) \mathrm{Cl}_{n}^{-(1+n-z)}+\mathrm{H}^{+}
$$

When $\mathrm{Fe}, \mathrm{Ni}$, and $\mathrm{Cr}$ were considered as metal $\mathrm{M}$, the following equations could be obtained by substituting $n=1$, or 2 and $z=2$ or 3 in Equation (4).

$$
\begin{aligned}
& \mathrm{Fe}^{2+}+\mathrm{H}_{2} \mathrm{O}+\mathrm{Cl}^{-}=\mathrm{Fe}(\mathrm{OH}) \mathrm{Cl}+\mathrm{H}^{+} \\
& \mathrm{Ni}^{2+}+\mathrm{H}_{2} \mathrm{O}+\mathrm{Cl}^{-}=\mathrm{Ni}(\mathrm{OH}) \mathrm{Cl}+\mathrm{H}^{+} \\
& \mathrm{Cr}^{3+}+\mathrm{H}_{2} \mathrm{O}+2 \mathrm{Cl}^{-}=\mathrm{Cr}(\mathrm{OH}) \mathrm{Cl}_{2}+\mathrm{H}^{+}
\end{aligned}
$$

Initial conditions of SCC crack solution and bulk solution are shown in Table $1^{1,7)}$.

\subsection{Electric circuit}

Electric Circuit 1 (anode + cathode 1) and Circuit 2 (anode + cathode 2) as shown in Fig. 2 can be assembled from the movement of charges of ions and electrons. Table 1 shows symbols of various resistances described in Fig. 2. The resistances caused by polarization at each electrode (called electrode resistance 
Table 1 Initial conditions of the SCC crack solution and the bulk solution

\begin{tabular}{l|ll}
\hline \multicolumn{1}{c|}{ Item } & Initial & Values \\
\hline <Crack solution> & & \\
- Concentration of $\mathrm{M}^{2+}$ Ions & 0.1 & $(\mathrm{M})$ \\
$\cdot \mathrm{pH}$ & 1.8 & $(-)$ \\
- Concentration of $\mathrm{H}^{+}$Ions & 0.01 & $(\mathrm{M})$ \\
- Concentration of Free $\mathrm{Cl}^{-}$Ions & 0.5 & $(\mathrm{M})$ \\
<Bulk Solution> & $0.5 \mathrm{M} \mathrm{NaCl}$ & Solution \\
<Temperature> & 298 & $(\mathrm{~K})$ \\
\hline
\end{tabular}

below) consist of activation polarization, concentration polarization, and solution resistance, and these are defined as the ratio of the polarization to the current. All kinds of electrode resistances, solution resistances, and metal resistances in each circuit were treated as linked, series processes. The electromotive forces of $E_{\mathrm{a}}, E_{\mathrm{c} 1}$, and $E_{\mathrm{c} 2}$ in Fig. 2 were obtained using the Nernst's equation as follows ${ }^{17), 18)}$.

$$
\begin{aligned}
& E_{\mathrm{a}}=E_{\mathrm{a} 0}+R T / 2 F \ln C_{\mathrm{Fe} 2+} \\
& E_{\mathrm{c} 1}=E_{\mathrm{c} 10}+R T / 4 F \ln \left(P_{\mathrm{O}_{2}} / P^{\mathrm{o}}\right) / C_{\mathrm{OH}}{ }^{-4} \\
& E_{\mathrm{c} 2}=E_{\mathrm{c} 20}+R T / 2 F \ln C_{\mathrm{H}^{+}} / C_{\mathrm{H} 2}
\end{aligned}
$$

where $E_{\mathrm{a}}, E_{\mathrm{c} 1}$, and $E_{\mathrm{c} 2}$ are the electromotive forces due to the oxidation of the metal at the crack tip (Equation(1)), the reduction of the oxygen on the external surface of the crack (Equation(2)), and the reduction of the hydrogen ions on the crack walls (Equation(3)), respectively as shown in Fig. 1. When mathematically solving the potential drop equations applied to two closed electric circuits shown in Fig. 2, the circuit currents of $I_{1}, I_{2}$ and $I\left(=I_{1}+I_{2}\right)$ can be obtained as follows.

$$
\begin{aligned}
I_{1} & =\left\{R_{\mathrm{c} 2} \times E_{\mathrm{a}}+\left(R_{\mathrm{c} 2}+R_{\mathrm{ap}}\right) E_{\mathrm{c} 1}-R_{\mathrm{ap}} \times E_{\mathrm{c} 2}\right\} / X \\
I_{2} & =\left\{R_{\mathrm{c} 1} \times E_{\mathrm{a}}-R_{\mathrm{ap}} \times E_{\mathrm{c} 1}+\left(R_{\mathrm{ap}}+R_{\mathrm{c} 1}\right) E_{\mathrm{c} 2}\right\} / X \\
I & =I_{1}+I_{2} \\
& =\left\{\left(R_{\mathrm{c} 1}+R_{\mathrm{c} 2}\right) E_{\mathrm{a}}+R_{\mathrm{c} 2} \times E_{\mathrm{c} 1}+R_{\mathrm{c} 1} \times E_{\mathrm{c} 2}\right\} / X, \\
& X=R_{\mathrm{ap}} R_{\mathrm{c} 2}+R_{\mathrm{c} 1} R_{\mathrm{ap}}+R_{\mathrm{c} 1} R_{\mathrm{c} 2 .}
\end{aligned}
$$

where $R_{\mathrm{ap}}$ is the resistance due to the polarization at the crack tip, $R_{\mathrm{c} 1}$ is the total resistances due to the electrode resistance on the crack external surface and solution resistances inside and outside the crack in the circuit 1 of Fig. 2, and $R_{\mathrm{c} 2}$ is the total resistance due to the electrode resistance on the crack walls and solution resistance inside the crack in the circuit 2 of Fig. 2.

\subsection{Estimation of various resistances}

For polarization at anode, cathode 1 and cathode 2 , activation polarization, concentration polarization and activation polarization respectively were considered since the initial concentration of solution in SCC crack was dilute in this model. Tafel's equation of $\eta=$ $b \times \log \left(i / i_{0}\right)$ was used as overvoltage $\eta$ for activation polarization, where, $b$ is Tafel constant, $i$ is current density and $i_{0}$ is exchange current density. The resistance of $R\left(R_{\mathrm{ap}}, R_{\mathrm{a}}\right)$ due to the overvoltage shown in
Table 2 was calculated using the equation $R=\eta /(S \times$ $i)$, where $S$ is the area of the electrode. Similarly, the equation $\eta=R g \times T / n F \ln \left(1-i / i_{\mathrm{L}}\right)$ was used to calculate overvoltage $\eta$ for concentration polarization, where $i_{\mathrm{L}}(=(n \times F \times D \times C) / \delta)$ is diffusion limiting current density. Where, $R g, T, n, F, i_{\mathrm{L}}, D, C$ and $\delta$ are gas constant, absolute temperature, charge number, Faraday constant, diffusion limiting current density, diffusivity of oxidizing agents $\left(\mathrm{O}_{2}, \mathrm{H}^{+}\right)$in aqueous solution, oxidizing agent concentration in bulk, and thickness of the diffusion layer, respectively ${ }^{18}$.

The electrode resistances of $R\left(R_{\mathrm{c} 10 \mathrm{~s}}\right)$ on the crack external surface (Table 2) were calculated using the equation $R=\eta /(S \times i)$. Specific resistance of crack solution was calculated using the equation $\rho=1000 /$ $(\Lambda \times C)$ when the equivalent conductivity of ion and the ion concentration are $\Lambda$ and $C$, respectively. The solution resistances of $R\left(R_{\mathrm{as},} R_{\mathrm{c} 1 \mathrm{~s}}, R_{\mathrm{c} 2 \mathrm{~s}}\right)$ shown in Table 2 were calculated using the equation $R=(\rho \times$ $l) / S_{f}$, where $S_{f}$ and $l$ are the cross section and the moving length of the charge, respectively, in the crack solution at $25^{\circ} \mathrm{C}$ containing $0.1 \mathrm{M}$ metal ions and 0.01 M hydrogen ions. $R_{\mathrm{as}}$ and $R_{\mathrm{c} 2 \mathrm{~s}}$ express resistances due to dissolved metal ions and hydrogen ions in crack, respectively. On the other hand, $R_{\mathrm{c} 1 \mathrm{~s}}$ represents solution resistance to movement of the charge outside the crack in the circuit 1 of Fig. 2.

A crack depth of $10 \mathrm{~mm}$ as to a and crack cross section of $10^{-4} \mathrm{~cm}^{2}$ as to $S_{f}$ were used for solution resistance of $R_{\mathrm{c} 1 \mathrm{~s}}$ due to the movement of dissolved metal ion $\mathrm{M}^{2+}$ in electric circuit 1 . On the other hand, a and $S_{1}$ for $R_{\mathrm{c} 2 \mathrm{~s}}$ due to movement of the hydrogen ion $\mathrm{H}^{+}$formed by hydrolysis reaction of metal ions were treated as follows. Since $\mathrm{H}^{+}$ions have a high mobility and undergo the force of the electric field perpendicular to the crack depth, they may move along the crack walls. Therefore, flowing cross section $(0.5 \times$ $10^{-4} \mathrm{~cm}^{2}$ ) with a half crack cross section and the mean flowing length $(5 \mathrm{~mm})$ with a half crack depth were assumed for the calculation of $R_{\mathrm{c} 2 \mathrm{~s}}$. Since specific resistance of metal is very small such as $\rho=9.7 \times 10^{-6}$ $\Omega \cdot \mathrm{cm}$ of iron, the metal resistance of $R\left(R_{\mathrm{c} 1 \mathrm{~m}}, R_{\mathrm{c} 2 \mathrm{~m}}\right)$ shown in Table 2 and in Fig. 2 was set at zero for calculation of circuit resistance.

\subsection{Rough estimate of resistance}

Table 2 shows the values of parameters to calculate various resistances in each electric circuit. The values of various resistances calculated from data shown in Table 1 are shown by unit of $\Omega$ in parenthesis in Table 2. In Table $2, R_{\mathrm{cl}}(934470(\Omega))$ is obtained as a result of the sum of $R_{\mathrm{c} 10}, R_{\mathrm{c} 10 \mathrm{~s}}, R_{\mathrm{c} 1 \mathrm{k}}, R_{\mathrm{as}}$ and $R_{\mathrm{c} 1 \mathrm{~s}}$. Similarly, $R_{\mathrm{c} 2}$ $(3026750(\Omega))$ is obtained as the sum of $R_{\mathrm{a}}, R_{\mathrm{cs}}, R_{\mathrm{c} 1 \mathrm{R}}$ ' and $R_{\mathrm{c} 2 \mathrm{~s}}$. These higher resistances in Table 2 could be due to the present SCC model. Thus, the solution resistance increased remarkably compared with 
Table 2 Symbols of various resistances used for electric circuit calculation shown in Fig. 2 and the rough calculated values of resistances shown in parenthesis

\begin{tabular}{|c|c|c|c|c|c|}
\hline \multirow{2}{*}{ Kinds of Resistances } & \multicolumn{4}{|c|}{ Symbols of Various Resistances* } & \multirow[b]{2}{*}{$R_{m 2}$} \\
\hline & $R_{\text {sp }}(191600)$ & $\mathrm{R}_{\mathrm{cl}}(934470)$ & $R_{-2}(3026750)$ & $R_{m l}$ & \\
\hline $\begin{array}{l}\text { Electrode Resistance } \\
\text { Solution Resistance } \\
\text { Metal Resistance }\end{array}$ & $R_{\text {ap }}(191600)$ & $\begin{array}{l}R_{c 100}(220) \\
R_{4}(934000) \\
+R_{c 10}(250)\end{array}$ & $\begin{array}{l}R_{i}(166750) \\
R_{c 2,}(2860000)\end{array}$ & $R_{m_{1}}(0$ & $R_{\mathrm{mp}}(0)$ \\
\hline
\end{tabular}

*: Values by unit of $\Omega$ in ( ) shows result of rough estimate of each resistance calculated

for the present model. Also, $R_{c 1}=R_{c 100}+R_{e q}+R_{c 1,}$ and $R_{c 2}=R_{c}+R_{c 2 s}$

polarization resistance due to the narrow width and long depth of the SCC crack shape. From Table 2, the following relation can be approximated with respect to $R_{\mathrm{ap}}, R_{\mathrm{c} 1}$ and $R_{\mathrm{c} 2}$.

$$
R_{\mathrm{c} 2}>R_{\mathrm{c} 1}>R_{\mathrm{ap}}
$$

When using this relation, circuit current $I_{1}$ and $I_{2}$ can be simplified as follows from Equations (8) and (9).

$$
\begin{aligned}
I_{1} & =\frac{E_{\mathrm{a}}+E_{\mathrm{cl}}}{R_{\mathrm{ap}}+R_{\mathrm{c} 1}}=\frac{E_{\mathrm{a}}+E_{\mathrm{c} 1}}{R_{\mathrm{c} 1}\left(1+R_{\mathrm{ap}} / R_{\mathrm{c} 1}\right)} \\
& =\frac{E_{\mathrm{a}}+E_{\mathrm{c} 1}}{\left(R_{\mathrm{c} 10}+R_{\mathrm{c} 10 \mathrm{~s}}+R_{\mathrm{as}}+R_{\mathrm{c} 1 s}\right)\left(1+R_{\mathrm{ap}} / R_{\mathrm{c} 1}\right)} \\
& =\frac{E_{\mathrm{a}}+E_{\mathrm{c} 1}}{\left(1+\frac{R_{\mathrm{c} 10}+R_{\mathrm{c} 10 \mathrm{~s}}+R_{\mathrm{c} 1 \mathrm{~s}}}{R_{\mathrm{as}}}\right) \times\left(1+\frac{R_{\mathrm{ap}}}{R_{\mathrm{c} 1}}\right) \times R_{\mathrm{as}}} \\
I_{2} & =\frac{E_{\mathrm{a}}+E_{\mathrm{c} 2}}{R_{\mathrm{ap}}+R_{\mathrm{c} 2}} \\
& =\frac{E_{\mathrm{a}}+E_{\mathrm{c} 2}}{R_{\mathrm{c} 2}\left(1+R_{\mathrm{ap}} / R_{\mathrm{c} 2}\right)}=\frac{E_{\mathrm{a}}+E_{\mathrm{c} 2}}{\left(R_{\mathrm{a}}+R_{\mathrm{c} 25}\right)\left(1+R_{\mathrm{ap}} / R_{\mathrm{c} 2}\right)} \\
& =\frac{E_{\mathrm{a}}+E_{\mathrm{c} 2}}{\left(1+\frac{R_{\mathrm{a}}}{R_{\mathrm{c} 2 \mathrm{~s}}}\right) \times\left(1+\frac{R_{\mathrm{ap}}}{R_{\mathrm{c} 2}}\right) \times R_{\mathrm{c} 2 \mathrm{~s}}}
\end{aligned}
$$

Also, Equation (13) can be expressed as follows.

$$
I_{1}=f \times C_{\mathrm{Fe}^{2+}}
$$

where, with respect to the resistance of $R_{\mathrm{ap}}=\eta_{\mathrm{a}} / i \times S_{\mathrm{a}}$ based on activation polarization at the anode, the anode area of $S_{\mathrm{a}}$ was replaced by a factor of $S_{\mathrm{a} 0} \times$ $\varepsilon\left(K_{1}\right)$, where $S_{\mathrm{a} 0}$ is independent of external force, or where $K_{\mathrm{I}}$ and $\varepsilon\left(K_{\mathrm{l}}\right)$ depend mainly on either the degree of plastic deformation at the crack tip by external force or $K_{\mathrm{I}}$. Also,

$$
\begin{aligned}
f= & \frac{E_{\mathrm{a}}+E_{\mathrm{cl}}}{\left(1+\frac{R_{\mathrm{c} 10 \mathrm{~s}}+R_{\mathrm{c} 1 \mathrm{~s}}}{R_{\mathrm{as}}}\right)\left(1+\frac{\eta_{\mathrm{a}}}{R_{\mathrm{cl}} \times i \times S_{\mathrm{a} 0} \times \varepsilon\left(K_{\mathrm{l}}\right)}\right)} \\
& \times \frac{\Lambda_{\mathrm{M}^{2}+} \times S_{\mathrm{SM}^{2+}}}{1000 \times l_{\mathrm{M}^{2+}}} \times 2
\end{aligned}
$$

Similarly, current $I_{2}$ of Equation (14) can be expressed as follows.

$$
I_{2}=g_{2} \times C_{\mathrm{H}^{+}}
$$

where

$$
g_{2}=\frac{E_{\mathrm{a}}+E_{\mathrm{c} 2}}{\left(1+\frac{R_{\mathrm{a}}}{R_{\mathrm{c} 2 \mathrm{~s}}}\right)\left(1+\frac{\eta_{\mathrm{a}}}{R_{\mathrm{c} 2} \times i \times S_{\mathrm{a} 0} \times \varepsilon\left(K_{1}\right)}\right)}
$$

$$
\times \frac{\Lambda_{\mathrm{H}^{+}} \times S_{\mathrm{H}^{+}}}{1000 \times l_{\mathrm{H}^{+}}}
$$

\subsection{Calculation of electromotive force of circuit}

The electromotive forces of $E_{\mathrm{a}}, E_{\mathrm{c} 1}$, and $E_{\mathrm{c} 2}$ can be obtained from Equations (5) to (7). Dissolved metal ions of $\mathrm{Fe}^{2+}$ were used for the calculation of $E_{\mathrm{a}}$. From Equation (5), the value of $-0.431(\mathrm{~V})$ as to $E_{\mathrm{a}}$ can be obtained using $C_{\mathrm{M}^{2}}=0.1(\mathrm{~mol} / \mathrm{L})$ shown in Table 1 and the standard electrode potential of $E_{\mathrm{a} 0}=-$ $0.440(\mathrm{~V} / \mathrm{SHE})$ regarding $\mathrm{Fe}=\mathrm{Fe}^{2+}+2 \mathrm{e}^{-} . E_{\mathrm{c} 1}$ was calculated for dissolved oxygen in neutral chloride solution. From Equation (6), the value of $+0.806(\mathrm{~V})$ as to $E_{\mathrm{c} 1}$ can be obtained using partial pressure of $P_{\mathrm{O}_{2}} / P^{0}=$ 0.2 to dissolved oxygen, the standard electrode potential of $E_{\mathrm{c} 10}=+0.401(\mathrm{~V} / \mathrm{SHE})$ regarding $\mathrm{O}_{2}+2 \mathrm{H}_{2} \mathrm{O}+$ $4 \mathrm{e}^{-} \rightarrow 4 \mathrm{OH}^{-}$, and $\mathrm{pH}=7$ of the bulk solution. Similarly, from Equation (7), the value of $-0.041(\mathrm{~V})$ as to $E_{\mathrm{c} 2}$ can be obtained using partial pressure of $P_{\mathrm{H}^{+}}=$ 1.0 as to hydrogen gas and the defined standard electrode potential of $E_{\mathrm{c} 20}=0.000(\mathrm{~V} / \mathrm{SHE})$ regarding $2 \mathrm{H}^{+}+2 \mathrm{e}^{-}=\mathrm{H}_{2}$.

\subsection{Time dependence of metal and hydrogen ion concentration in crack solution}

Assuming that dissolution of metal occurs only at the SCC crack tip as a result of the anode reaction, the total current of $I$ shows the amount of electricity of metal ion $\mathrm{M}^{2+}$ dissolving from the anode (crack tip) per unit time. Therefore, when the volume of crack solution into which metal ions flow from the crack tip is $V$, the concentration of metal ions corresponding to $I / z F V(\mathrm{~mol} / \mathrm{L})$ may accumulate in an SCC crack solution per unit time.

On the other hand, $\mathrm{H}^{+}$ion concentration of $I_{2} / F V$ $(\mathrm{mol} / \mathrm{L})$ per unit time in a crack solution may decrease on account of the flow of cathode current $I_{2}$ at cathode 2. It was assumed that the concentrations of both free chloride ions and hydroxy-chlorocomplexes formed by hydrolysis were constant in the solution reaction of Equation (4).

Also in Equations (4) to (4c), it was assumed that the activity of $\mathrm{H}_{2} \mathrm{O}$ was about 1.0 and the activity of $\mathrm{M}(\mathrm{OH}) \mathrm{Cl}$ or $\mathrm{M}(\mathrm{OH}) \mathrm{Cl}_{2}$ was about 1.0 since these 
complexes could be regarded to exist as hydrated gels or oligomers ${ }^{19}$. From Equations (4), (15), and (17), the time dependence of concentrations of $\mathrm{M}^{2+}$ ions and $\mathrm{H}^{+}$ions in the $\mathrm{SCC}$ crack solution can be expressed by the following rate equations ${ }^{8)}$.

$$
\frac{\mathrm{d} C_{\mathrm{H}^{+}}}{\mathrm{d} t}=-g_{2} \times C_{\mathrm{H}^{+}} / F V-k_{-1} \times C_{\mathrm{H}^{+}}+k_{1} \times C_{\mathrm{Cl}^{-}} \times C_{\mathrm{M}^{2+}}
$$

$$
\begin{aligned}
\frac{\mathrm{d} C_{\mathrm{M}^{2+}}}{\mathrm{d} t}= & \left(f \times C_{\mathrm{M}^{2+}}+g_{2} \times C_{\mathrm{H}^{+}}\right) / z F V+k_{-1} \times C_{\mathrm{H}^{+}}-k_{1} \\
& \times C_{\mathrm{Cl}^{-}} \times C_{\mathrm{M}^{2+}}
\end{aligned}
$$

where $k_{1}$ and $k_{-1}$ are the reaction rate constants of the forward and reverse reactions of Equation (4), respectively, and $z$ is the charge number of the metal ions. In Equations (19) and (20), the accumulation of metal ions and hydrogen ions per unit time is based on the assumption that these ions do not move into the bulk solution. It can be considered that this assumption may be reasonable in the case of the events underneath the deposits. Though the crack volume $V$ increases with the growth of the crack, it is assumed as a constant because the increase in the volume containing the accumulated ions can be assumed to be smaller than the degree of accumulation of metal ions and hydrogen ions. In this model with a high aspect ratio, although ion concentration may be actually different along the crack depth due to diffusion or migration of ions, it is assumed to be everywhere uniform in order to describe approximately the crack solution as one of many circuit resistances. The coefficient $f$ can be regarded as a constant for the change of metal ion concentration if the relations of $R_{\mathrm{as}}>$ $R_{\mathrm{c} 10 \mathrm{~s}}+R_{\mathrm{c} 1 \mathrm{~s}}$ and $R_{\mathrm{c} 1}>R_{\mathrm{ap}}$ hold as understood from Equations (13) and (16). Similarly, the coefficient $g_{2}$ can be regarded as a constant for the change of hydrogen ion concentration as understood from Equations (14) and (18) if the relations of $R_{\mathrm{c} 2 \mathrm{~s}}>R_{\mathrm{a}}$ and $R_{\mathrm{c} 2}>R_{\mathrm{a}}$ hold as well as $f$. Assuming that $k_{1}$ and $k_{-1}$ of the complex reaction of Equation (4) are so large that the relation of $k_{1}, k_{-1} \gg f, g_{2}$ holds and $f, g$ and $\varepsilon\left(K_{1}\right)$ are constant with time, the following expressions can be obtained by solving the simultaneous differential equations shown in Equations (19) and (20).

$$
C_{\mathrm{M}^{2+}}=C_{\mathrm{M}^{2+0}} \times \exp \left\{\left[\frac{f-g_{2} C_{\mathrm{Cl}^{-}} K}{z F V\left(1+C_{\mathrm{Cl}}-K\right)}\right] \times t\right\}
$$

Also,

$$
C_{\mathrm{H}^{+}}=C_{\mathrm{H}^{+0}} \times \exp \left\{\left[\frac{f-g_{2} C_{\mathrm{Cl}}-K}{z F V\left(1+C_{\mathrm{Cl}-K}-K\right.}\right] \times t\right\}
$$

therefore,

$$
\begin{aligned}
I_{1}= & f \times C_{\mathrm{M}^{2+}}=f \times C_{\mathrm{M}^{2+0}} \\
& \times \exp \left\{\left[\frac{f-g_{2} C_{\mathrm{Cl}}-K}{z F V\left(1+C_{\mathrm{Cl}}-K\right)}\right] \times t\right\} \\
I_{2}= & g_{2} \times C_{\mathrm{H}^{+}}=g_{2} \times C_{\mathrm{H}^{+0}} \\
& \times \exp \left\{\left[\frac{f-g_{2} C_{\mathrm{Cl}}-K}{z F V\left(1+C_{\mathrm{Cl}}-K\right)}\right] \times t\right\}
\end{aligned}
$$

regarding total current,

$$
I=I_{1}+I_{2}=f \times C_{\mathrm{M}^{2+}}+g_{2} \times C_{\mathrm{H}^{+}}=\left(f \times C_{\mathrm{M}^{2+0}}+g_{2}\right.
$$

$$
\left.\times C_{\mathrm{H}^{+0}}\right) \times \exp \left\{\left[\frac{f-g_{2} C_{\mathrm{Cl}} K}{z F V\left(1+C_{\mathrm{cl}-}-K\right)}\right] \times t\right\}
$$

where, $K$ is the equilibrium constant or stability constant of Equation (4), and $K=k_{1} / k_{-1} . C_{\mathrm{M}^{2+0}}$ and $C_{\mathrm{H}+0}$ show the initial concentrations of metal ions and hydrogen ions at time 0 , respectively.

\section{Results and Discussion}

\subsection{Meaning of threshold stress intensity factor $\left(K_{\mathrm{IScC}}\right)$}

Lower $\mathrm{pH}$ (concentrated hydrogen ions) or highly concentrated metal ions were observed inside the crack or inside the crevice in chloride environments ${ }^{7) .29}$. And the mathematical model showed that metal ion concentration (Equation(21)) and hydrogen ion concentration (Equation(22)) could be increased exponentially regarding a product of time of $t$ and a facter of $f-C_{\mathrm{Cl}^{-}} \times K \times g_{2}$ with total current (Equation(25)) showing the metal dissolution at crack tip. It can be understood that these relations are decided by adding or subtracting the value of $f-C$ $\mathrm{ct}^{-} \times K \times g_{2}$. Namely, it can be understood that crack can not grow when $f-C_{\mathrm{Cl}^{-}} \times K \times g_{2}<0$, and conversely, that it can grow when $f-C_{\mathrm{Cl}^{-}} \times K \times g_{2}>0$. Further, it can be understood that the stress intensity factor $K_{\mathrm{l}}$ which satisfies the equation $f-C_{\mathrm{Cl}^{-}} \times K \times g_{2}=0$ may be $K_{\mathrm{tscc}}$. Since external force can give rise to the remarkable plastic deformation at the crack tip, numerous active slip planes due to slip of dislocations ${ }^{20)}$ and many defects (active points) such as kink, step, vacancy, etc. ${ }^{21)}$ may be formed on a small anode surface at the crack tip. As a result, it can be expected that the anode area and active points from which the metal dissolves increases remarkably with increases in the external force or $K_{\mathrm{l}}$. The factor $\varepsilon\left(K_{1}\right)$ shown in Equations (16) and (18) can be regarded as a parameter which corresponds to the degree of actual increase in the dissolving area of an anode under the external force. Thus, $\varepsilon\left(K_{\mathrm{l}}\right)$ equals 1 when external force does not exist, and $\varepsilon\left(K_{1}\right)$ can be expected to become greater as $K_{\mathrm{l}}$ is increased. $\mathrm{Na}$ kayama et $\mathrm{al}^{20), 22)}$. observed the SCC crack tip of Type 304 stainless steel tested in $2.5 \mathrm{M} \mathrm{H}_{2} \mathrm{SO}_{4}+0.5 \mathrm{M} \mathrm{NaCl}$ and $20 \% \mathrm{NaCl}$ solution at room temperature and $100^{\circ} \mathrm{C}$ using a high voltage electron microscope (HVEM). They pointed out that in the case of a low stress level, the crack growth could be caused mainly by dissolution of active slip planes, and in the case of a high stress level, preferential dissolution, hydrogen embrittlement, martensite phases, and hydrogen were observed.

In a study on the effect of strain on the anodic dissolution kinetics of an fcc metal which can slide on the (111) slip plane only, Despic et $\mathrm{al}^{23)}$. estimated the rate of the dissolution at slip edges was about 10 times 


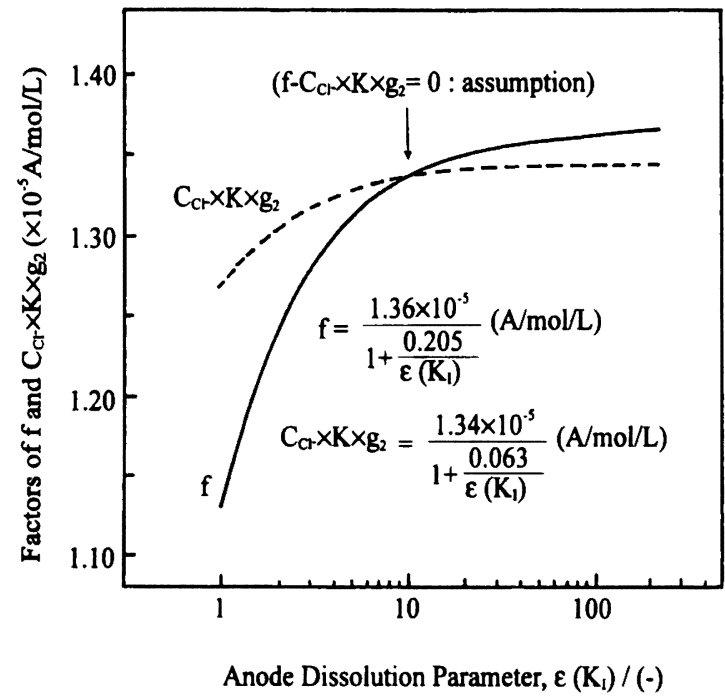

Fig. 3 Simulated results of relationship between factors of $f$ and $C_{\mathrm{C} t} \times K \times g_{2}$ and anode dissolution parameter of $\varepsilon\left(K_{1}\right)$ in $0.1 \mathrm{M}$ metal ion $+0.01 \mathrm{M}$ hydrogen ion solution at room temperature.

larger than that at the unstrained metal. In the present environment, $\varepsilon\left(K_{1}\right)$ of 10.0 was assumed in the calculation of circuit current in the SCC growing process. Fig. 3 shows the $\varepsilon\left(K_{1}\right)$ dependence of $f, g_{2}$ and $C_{\mathrm{C}^{-}} \times$ $K \times g_{2}$. As the Figure shows, the $f$ and $g_{2}$ curves tend to increase slightly with increases in $\varepsilon\left(K_{1}\right)$. In the curve of $C_{\mathrm{Cl}^{-}} \times K \times g_{2}, C_{\mathrm{Cl}^{-}} \times K=1.16$ is calculated and the curve intersects the curve of $f$ at $\varepsilon\left(K_{1}\right)=10$. If $\varepsilon\left(K_{1}\right)<10$, the crack cannot grow because $f-C_{c_{1}-} \times$ $K \times g_{2}$ becomes negative. On the other hand, if $\varepsilon\left(K_{1}\right)>10$, it can grow because $f-C_{\mathrm{Cl}^{-}} \times K \times g_{2}$ becomes positive.

It can be understood in Fig. 3 that the slopes of increase in $f$ regarding $\varepsilon\left(K_{1}\right)$ are more than those in $C_{\mathrm{Cl}-} \times K \times g_{2}$ and it may successfully explain a relationship between SCC crack growth rate and stress intensity factor obtained experimentally so far. If the degrees of the slopes of these two curves are reversed, the large and small relation between $f$ and $C_{\mathrm{C}^{-}} \times K \times$ $g_{2}$ reverses and the crack will grow only in the range up to $K_{\text {Iscc }}$. However, this is opposed to the fact. Therefore, to properly understand the existence of $K_{\mathrm{Iscc}}$ and the growth of SCC crack, the resistance of $R_{\mathrm{c} 2}$ in an electric circuit 2 must be larger than that of $R_{\mathrm{c} 1}$ in the electric circuit 1 as understood in Equations (16) and (18). Namely, the following condition is necessary for the existence of the threshold stress intensity factor of $K_{\mathrm{Iscc}}$ for 18-8 austenitic stainless steel in a chloride environment.

$$
\begin{aligned}
& R_{\mathrm{c} 2} \text { (circuit } 2: \mathrm{H}^{+} \text {reduction) }>R_{\mathrm{c} 1} \text { (circuit } 1: \mathrm{O}_{2} \\
& \quad \text { reduction) }
\end{aligned}
$$

Also, it can be understood from Fig. 3 that the curve of $g_{2}$ may not intersect the curve of $f$ when the value of $C_{\mathrm{Cl}^{-}} \times K$ is not large enough. Accordingly, the value of $C_{\mathrm{C}^{-}} \times K$, the product of the free chloride ion concentration of $C_{\mathrm{Cl}^{-}}$and the equilibrium constant of Equation (4) inside the crack solution, may also have to be high as a necessary condition for the existence of $K_{\text {Iscc. }}$.

As to $\varepsilon\left(K_{1}\right)$, sufficient quantitative studies were not performed ${ }^{23}$. Since $\varepsilon\left(K_{\mathrm{l}}\right)$ can be regarded as a parameter expressing the degree of the dissolved amount of metal, plastic deformations, formation of lattice defects, diffusion of hydrogen atom into the metal, etc. must be studied to clarify the concrete shape of $\varepsilon\left(K_{1}\right)$.

\section{$3.2 \mathrm{~K}_{\mathrm{I}}$ dependence of $\mathrm{SCC}$ growth rate}

The SCC growth rate $\mathrm{d} a / \mathrm{d} t$ can be given by the following equation ${ }^{24)}$.

$$
\frac{\mathrm{d} a}{\mathrm{~d} t}=\frac{M I}{n F S \rho}
$$

where, $M, I, n, F, S$, and $\rho$ are atomic mass, dissolving current at anode, charge number of metal ion, Faraday constant, anode area, and metal density, respectively.

In 18-8 austenitic stainless steel, $\mathrm{d} a / \mathrm{d} t$ after $t$ hours in the $25^{\circ} \mathrm{C}$ crack solution containing $0.1 \mathrm{M}$ metal ions, $0.01 \mathrm{M}$ hydrogen ions, and $0.5 \mathrm{M}$ free chloride ions under the initial condition can be obtained by the next equation calculated from Table 3 , where $56(\mathrm{~g} /$ $\mathrm{mol}), 8.0\left(\mathrm{~g} / \mathrm{cm}^{3}\right)$, and $0.7(-)$ are the atomic mass of iron, density of $18-8$ stainless steel, and the product of the apparent equilibrium constant and free chloride ion concentration in the crack solution, respectively. In Table 3, the origin of each parameter is shown at the column of reference or source. In the column, the parameter values as to (17), (23), (25), (26) and (27) were referred by the literatures, also polarization values and diffusion limiting current density were calculated using the equations shown in paragraph 2.4 in this paper, and current density and the area at each electrode were assumed so that total anode current equaled to total cathode current, and moving distances and flowing areas of ions in solution were assumed considering the dimensions of this crack model.

$$
\begin{aligned}
\frac{\mathrm{d} a}{\mathrm{~d} t}= & \left\{\frac{1.36 \times 10^{-6}}{1+\frac{0.205}{\varepsilon\left(K_{\mathrm{I}}\right)}}+\frac{1.16 \times 10^{-7}}{1+\frac{0.063}{\varepsilon\left(K_{\mathrm{I}}\right)}}\right\} \\
& \times \exp \left\{\left[\frac{3.27 \times 10^{-4}}{1+\frac{0.205}{\varepsilon\left(K_{\mathrm{I}}\right)}}-\frac{3.22 \times 10^{-4}}{1+\frac{0.063}{\varepsilon\left(K_{\mathrm{I}}\right)}}\right] \times t\right\}
\end{aligned}
$$

Fig. 4 shows simulated results of the relationships between $\varepsilon\left(K_{1}\right)$ and $\mathrm{d} a / \mathrm{d} t$ after 0,50 , and 100 hours when the initial concentrations for metal and hydrogen ions are $0.1 \mathrm{M}\left(C_{\mathrm{M}^{2+0}}\right)$ and $0.01 \mathrm{M}\left(C_{\mathrm{H}^{+0}}\right)$, respectively. Each curve regarding a relationship between $\mathrm{d} a / \mathrm{d} t$ and $\varepsilon\left(K_{1}\right)$ shows the value of different thresh- 
Table 3 Parameters and the values used for calculation of various resistances with respect to anode, cathode 1 , cathode 2 and solution.

\begin{tabular}{|c|c|c|c|}
\hline Parameter & Value & Unit & $\begin{array}{c}\text { Reference or } \\
\text { Source }\end{array}$ \\
\hline 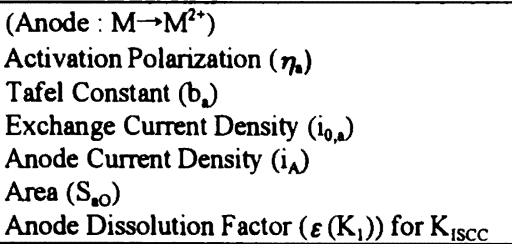 & $\begin{array}{c}0.479 \\
0.075 \\
10^{-3} \\
0.025 \\
10^{-4} \\
10\end{array}$ & $\begin{array}{l}(\mathrm{V}) \\
(\mathrm{V} / \text { decade }) \\
\left(\mathrm{A} / \mathrm{cm}^{2}\right) \\
\left(\mathrm{A} / \mathrm{cm}^{2}\right) \\
\left(\mathrm{cm}^{2}\right) \\
(-)\end{array}$ & $\begin{array}{l}\text { calculated } \\
\text { (25) } \\
\text { (17) } \\
\text { assumed } \\
\text { assumed } \\
\text { (23) }\end{array}$ \\
\hline $\begin{array}{l}\left.\text { Cathode } 1: \mathrm{O}_{2} \rightarrow \mathrm{OH}\right) \\
\text { Area }\left(\mathrm{S}_{\mathrm{cl}}\right) \\
\text { Concentration Polarization }\left(\eta_{\mathrm{clm}}\right) \\
\text { Dissolved Oxy gen Diffusivity }\left(\mathrm{D}_{02}\right) \\
\text { Dissolved Oxygen Concentration }\left(\mathrm{C}_{02}\right) \\
\text { Thickness of Diffusion Layer }\left(\delta_{\mathrm{cl}}\right) \\
\text { Diffusion Limiting Current Density }\left(\mathrm{i}_{\mathrm{L}, \mathrm{O}_{2}}\right) \\
\text { Cathode Current Density }\left(\mathrm{i}_{\mathrm{c}}\right)\end{array}$ & $\begin{array}{c}4.0 \\
0.059 \\
2.41 \times 10^{-5} \\
7.1 \times 10^{-7} \\
0.01 \\
3.3 \times 10^{-4} \\
5.0 \times 10^{-6} \\
\end{array}$ & $\begin{array}{l}\left(\mathrm{cm}^{2}\right) \\
(\mathrm{V}) \\
\left(\mathrm{cm}^{2} / \mathrm{s}\right) \\
\left(\mathrm{mol} / \mathrm{cm}^{3}\right) \\
(\mathrm{cm}) \\
\left(\mathrm{A} / \mathrm{cm}^{2}\right) \\
\left(\mathrm{A} / \mathrm{cm}^{2}\right)\end{array}$ & $\begin{array}{l}\text { assumed } \\
\text { calculated } \\
(26) \\
(27) \\
\text { (17) } \\
\text { calculated } \\
\text { assumed }\end{array}$ \\
\hline $\begin{array}{l}\left(\text { Cathode } 2: \mathrm{H}^{+} \rightarrow \mathrm{H}_{2}\right) \\
\text { Activation Polarization }\left(\eta_{\mathrm{c}_{20}}\right) \\
\text { Tafel Constant }\left(\mathrm{b}_{\mathrm{cz2}}\right) \\
\text { Exchange Current Density }\left(\mathrm{i}_{0,}, \mathrm{c2}\right) \\
\text { Area }\left(\mathrm{S}_{\mathrm{c} 2}\right) \\
\text { Cathode Current Density }\left(\mathrm{i}_{\mathrm{c} 2}\right) \\
\end{array}$ & $\begin{array}{c}0.083 \\
0.12 \\
5 \times 10^{-7} \\
0.202 \\
2.47 \times 10^{-6} \\
\end{array}$ & $\begin{array}{l}(\mathrm{V}) \\
\text { (V/decade) } \\
\left(\mathrm{A} / \mathrm{cm}^{2}\right) \\
\left(\mathrm{cm}^{2}\right) \\
\left(\mathrm{A} / \mathrm{cm}^{2}\right) \\
\end{array}$ & $\begin{array}{l}\text { Calculated } \\
(17) \\
(17) \\
\text { assumed } \\
\text { assumed }\end{array}$ \\
\hline $\begin{array}{l}\text { (Solution) } \\
\text { Metal Ion Equivalent Conductivity }\left(\Lambda_{\mathrm{M}^{+}}\right) \\
\text {Hydrogen Ion Equivalent Conductivity }\left(\Lambda_{\mathrm{H}^{+}}\right) \\
\text {OH' Ion Equivalent Conductivity }\left(\Lambda_{\mathrm{Cl}^{-}}\right) \\
\text {Moving Distance of Metal Ion }\left(\lambda_{\mathrm{M2}_{2+}}\right) \\
\text { Moving Distance of } \mathrm{H}^{+} \text {Ion }\left(\lambda_{\mathrm{H}^{+}}\right) \\
\text {Flowing Area of Metal Ion }\left(\mathrm{S}_{\mathrm{SM}_{2+}}\right) \\
\text { Flowing Area of } \mathrm{H}^{+} \text {Iron }\left(\mathrm{S}_{\mathrm{SH}^{+}}\right) \\
\end{array}$ & $\begin{array}{c}53.5\left(\text { for } \mathrm{Fe}^{2+}\right) \\
349 \\
76.3 \\
10.0 \\
5.0 \\
10^{-4} \\
0.5 \times 10^{-4} \\
\end{array}$ & $\begin{array}{l}\left(\Omega^{-1} \mathrm{~cm}^{2} \text { equiv }{ }^{-1}\right) \\
\left(\Omega^{-1} \mathrm{~cm}^{2} \text { equiv }{ }^{-1}\right) \\
\left(\Omega^{-1} \mathrm{~cm}^{2} \text { equiv }\right) \\
(\mathrm{mm}) \\
(\mathrm{mm}) \\
\left(\mathrm{cm}^{2}\right) \\
\left(\mathrm{cm}^{2}\right) \\
\end{array}$ & $\begin{array}{l}(27) \\
(27) \\
(27) \\
\text { assumed } \\
\text { assumed } \\
\text { assumed } \\
\text { assumed }\end{array}$ \\
\hline
\end{tabular}

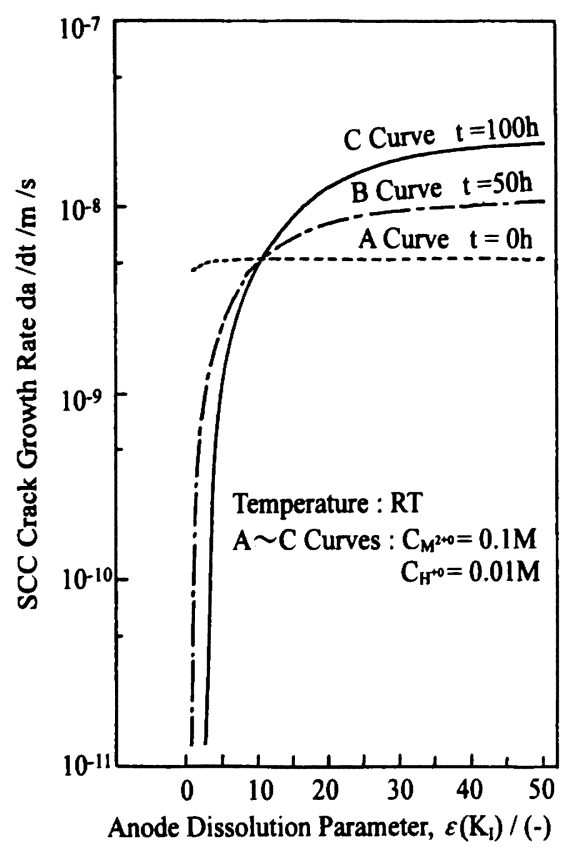

Fig. 4 Simulated results of relationship between SCC crack growth rate of $\mathrm{d} a / \mathrm{d} t$ and anode dissolution parameter of $\varepsilon\left(K_{1}\right)$ with respect to various times at room temperature. old. It increases rapidly when $\varepsilon\left(K_{1}\right)$ exceeds the range of 0 to 5 , and quickly attains a saturated condition. A $\mathrm{d} a / \mathrm{d} t$ value of about $10^{-8}(\mathrm{~m} / \mathrm{s})$ is obtained for periods of 0 to 100 hours.

Tsujikawa et $\mathrm{al}^{5)}$. have showed the about $10^{-9} \mathrm{~m} / \mathrm{s}$ growth rate in the region II of Type 316 stainless steel in $3 \% \mathrm{NaCl}$ solutions at $25^{\circ} \mathrm{C}$ under $K_{1}$ constant condition. Also Zuo et al. ${ }^{11}$ have showed that the growth rate in the region II of $18-8$ austenitic stainless steel were about $5 \times 10^{-8}$ to $1 \times 10^{-7}(\mathrm{~m} / \mathrm{s})$ in various solutions containing metallic ions and hydrogen ions at $90^{\circ} \mathrm{C}$. Therefore, it can be considered that these values of about $10^{-8}(\mathrm{~m} / \mathrm{s})$ simulated in this paper are reasonable to SCC growth rate of 18-8 stainless steel in chloride solution at $25^{\circ} \mathrm{C}$.

\subsection{Anode dissolution parameter corresponding to $K_{\text {Iscc }}$}

From an equation of $f-C_{\mathrm{Cl}^{-}} \times K \times g_{2}=0$ of a threshold condition of SCC growth rate in equation(25), an anode dissolution parameter $\varepsilon\left(K_{\mathrm{ISCC}}\right)$ corresponding to $K_{\mathrm{Iscc}}$ is derived as follows when $\mathrm{A}_{0}$ is constant.

$$
\varepsilon\left(K_{\mathrm{ISc}}\right)=\frac{R_{\mathrm{ap}}}{(1-\omega)} \times\left(\frac{\omega}{R_{\mathrm{c} 1}}-\frac{1}{R_{\mathrm{c} 2}}\right)
$$

where

$$
\omega=A_{0} \times\left(\frac{E_{\mathrm{a}}+E_{\mathrm{c} 2}}{E_{\mathrm{a}}+E_{\mathrm{c} 1}}\right) \times\left(\frac{\Lambda_{\mathrm{H}^{+}}}{\Lambda_{\mathrm{Fe}^{2+}}}\right) \times\left(\frac{S_{\mathrm{H}^{+}}}{S_{\mathrm{SM}^{2+}}}\right) \times\left(\frac{l_{\mathrm{M}^{2+}}}{l_{\mathrm{H}^{+}}}\right)
$$




$$
\times\left(\frac{1+\frac{R_{\mathrm{c} 10 \mathrm{~s}}+R_{\mathrm{cls}}}{R_{\mathrm{as}}}}{1+\frac{R_{\mathrm{a}}}{R_{\mathrm{c} 2 \mathrm{~s}}}}\right)
$$

From equations (29) and (30), it is predicted that $\varepsilon\left(K_{\mathrm{ISCC}}\right)$ depends on many parameters and increases remarkably as $R_{\mathrm{ap}}$ (electrode resistance of an anode) is larger and parameter $\omega$ approaches unity.

\section{Conclusions}

We quantitatively studied a mathematical model (electric circuit model) to understand an existence of the threshold stress intensity factor of $K_{\mathrm{Iscc}}$ in the process of growth of the stress corrosion cracking (SCC) based mainly on the slip-dissolution model of 18-8 austenitic stainless steel under a chloride environment using electric circuit theory and a parallelsided crack model. As a result, the following items can be concluded.

(1) The existence of $K_{\mathrm{tScc}}$ may be caused by the following major conditions.

- The two physically separated cathodes involving $\mathrm{H}^{+}$reduction in the crack and the $\mathrm{O}_{2}$ reduction outside the crack entrance ( 1 anode -2 cathode system).

- A solution resistance which is higher than the resistance of activation and concentration polarization.

- A solution resistance due to hydrogen ion which is higher than that due to dissolved metal ion in the SCC crack solution.

- High value of the product of the equilibrium constant and free chloride ion concentration in the SCC crack solution.

(2) An SCC crack growth rate of about $10^{-8} \mathrm{~m} / \mathrm{s}$, close to the data obtained experimentally so far, could be calculated theoretically using the equation derived from the present electric circuit model.

(3) It is predicted that an anode dissolution parameter $\varepsilon\left(K_{\mathrm{iscc}}\right)$ corresponding to $K_{\mathrm{tscc}}$ increases largely as an electrode resistance at anode becomes larger and parameter $\omega$ depends on many factors approaches unity.

\section{Acknowledgment}

The author thanks Dr K. Fujita of Kure Research Laboratory for his help in writing the manuscript. The author also wish to thank Professor K.Sugimoto of Tohoku University for his helpful discussion and suggestions on the electrochemical process.

\section{References}

1) J.Y. Zuo, B.X. Gu and Y.P. Liu: Corrosion, 47, 47 (1991).

2) M. Kowaka and K. Yamanaka : J. Japan Inst. Metals, 44, 800 (1980).

3) Y. Mukai and M. Murata: Bulletin of Japan Inst. Metals, 20, 12 (1981).

4) Th. Fröhlich, W. Schwenk and W. Dahl : Materials and Corrosion, 48, 207 (1997).

5) S. Tsujikawa, K. Tamaki and Y. Hisamatsu : Tetsu-tohagane, 66, 2067 (1980).

6) H. Sunaga : "Sutenresuko no Sonsho to cono boshi", Nikkan kogyo shinbunsha, p.7-33 (1981).

7) T. Suzuki, M. Yamabe and Y. Kitamura : Corrosion, 29, 18 (1973).

8) Y. Tsuksue : Proceedings of JSCE Corrosion '95, p.259 (1995).

9) A. Turnbull : Corrosion Science, 39, 789 (1997).

10) D.D. Macdonald and M. Ur-Macdonald: Corrosion Science, 32, 51 (1991).

11) D.A. Vermilyea : J. electrochem. Soc., 119, 405 (1972).

12) J. Baes and W. Mesmer: "The Hydrolysis of Cations" New York, NY : John Wiley and Sons, (1976).

13) P.O. Zang, J.X. Wu, W.O. Zhang, X.Y. Lu and K. Wang: Corrosion Science, 34, 1343 (1993).

14) Y.H. Lee, Z. Takehara and S. Yoshizawa : Proceedings of 24th Japan Corrosion Conference, p.139 (1977)

15) T. Adachi, T. Yoshii and T. Maekita: Tetsu-toHagane, 65, 54 (1977).

16) H. Ogawa, M. Nanata, I. Itoh, Y. Hosoi and $H$. Okada: Tetsu-to-hagane, 66, 1385 (1980).

17) J.M. West : "Basic Corrosion and Oxidation", (1980).

18) T. Oki : "Kinzoku denkikagaku", kyoritsu shuppan, p. 51 (1991).

19) M. Watson and J. Postlethwaite : Corrosion, 46, 522 (1990).

20) T. Nakayama and M. Takano: Corrosion, 38, 1 (1982).

21) N. Otani: Tetsu-to-Hagane: NO.5, 556 (1979).

22) M. Takano and T. Nakayama : Bulletin of Japan Inst. Metals, 21, 809 (1982).

23) A.R. Despic, R.G. Raicheff and J.O'M. Bockris: J. Chem. Physics, 49, 926 (1968).

24) M.P. Manahan, D.D. Macdonaldo and A.J. Peterson : Corrosion Science, 37, 189 (1995).

25) D. Tromans and L.Frederik : Corrosion, 39, 305 (1983).

26) Kagaku Kogaku Kyokai : "Bussei Constants 4ed.", (1966).

27) Nihon Kagakukai: Kagaku Binran Kisohen(3rd), Marzen, (1970)

28) M. Takahashi : Boshoku-gijutsu, 23, 625 (1974).

29) K. Komai : "Kankyo - Koon Kyodo-gaku" No.7, Omusha, p.46 (1984).

(Manuscript received November 16, 1999 : in final form January 21,2000 ) 